\title{
Processos cognitivos envolvidos na percepção do risco na paisagem: O caso dos moradores da Barragem do Departamento Nacional de Saneamento e Obras (DNOS), na cidade de Santa Maria - RS.
}

Cognitive process involved in the perception of risk in the landscape: the case of residents of National Department of Works and Sanitation Dam (DNOS), in the city of Santa Maria - RS

\author{
Rafael Silveira da Silva', Maria da Graça Barros Sartori², Cássio Arthur Wollmann² \\ ' Universidade Federal de Santa Maria (UFSM), PPGGEO - Santa Maria - RS - Brasil \\ ${ }^{2}$ Universidade Federal de Santa Maria (UFSM), Departamento de Geociências, PPGGEO/UFSM - Santa Maria - RS - Brasil
}

\begin{abstract}
Resumo
O objetivo principal da pesquisa foi diagnosticar os aspectos relacionados à percepção do risco na paisagem pela população do entorno da Barragem do DNOS, localizada na cidade de Santa Maria - RS. Foram entrevistados 47 pessoas, ambos os sexos, acima de 21 anos de idade. Os entrevistados foram aleatoriamente convidados a apresentarem suas percepções individuais sobre a identidade, por meio de preenchimento de um formulário de entrevista, com perguntas abertas e fechadas, composto por duas partes. A metodologia utilizada foi a sugerida por Whyte (1977) e igualmente utilizada por Sartori (2000), que consiste em um triângulo metodológico de pesquisa formado pela tríade observando, perguntando e ouvindo e registrando. Na análise e tabulação dos dados, constatou-se que dos 47 entrevistados $75 \%$ são mulheres e 25\% homens, com predomínio de idades entre 21 e 60 anos ou mais e tempo de residência de 6 meses a 50 anos. Em relação à questão que aborda o sentido afetivo (topofilia) se o entrevistado gostaria de morar em outro lugar. $72 \%$ dos entrevistados responderam que não gostariam de morar em outro lugar; $10 \%$. Os estudos futuros nessa área devem considerar populações mais amplas, de vários níveis socioeconômicos e educacionais.
\end{abstract}

Palavras-chave: Percepção; Paisagem; Riscos Ambientais; Barragem DNOS; Santa Maria/RS.

\begin{abstract}
The main objective of this research concerned in to diagnose the aspects related to the perception of risk in the landscape surrounding population DNOS Dam, located in Santa Maria - RS. We interviewed 47 people, both male and female, above 21 years of age. Respondents were randomly invited to submit their individual perceptions of identity through completing an interview form, with open and closed questions, consists of two parts. The methodology used was suggested by Whyte (1977) and also used by Sartori (2000), which consists of a triangle methodological research triad formed by observing, asking and listening and recording. In the analysis and tabulation of data, it was found that of the 47 respondents $75 \%$ are women and $25 \%$ men, with a prevalence of between 21 and 60 years or older and residence time of 6 months to 50 years. Regarding the question that addresses the affective meaning (topophilia) whether the respondent would like to live somewhere else. $72 \%$ of respondents would not want to live anywhere else; $10 \%$. Future studies in this area should consider broader populations of various educational and socioeconomic levels.
\end{abstract}

Keywords:Perception; Landscape; Environmental Risks; DNOS Dam; Santa Maria / RS. 


\section{INTRODUCCÃO}

Nas últimas décadas, tendo em vista o crescimento acelerado das cidades brasileiras, a expansão urbana tem avançado sobre regiões inadequadas a esse tipo de uso do solo. Constatase, por exemplo, a ocupação de áreas de várzeas, áreas sujeitas à inundação, áreas com elevadas declividades ou sujeitas a processos erosivos ou ainda a implantação de loteamentos em zonas de solos com baixa capacidade de carga.

Nesse sentido, o risco associado à ocorrência de desastres tem sido um dos principais focos de estudo de várias das principais instituições nacionais, tais como institutos de pesquisa, centros universitários ou órgãos governamentais. Os danos materiais e, principalmente, humanos, verificados em desastres como os ocorridos em novembro de 2008, em Santa Catarina, os deslizamentos que atingiram o Morro do Bumba, no Rio de Janeiro, e a devastação causada pelas enxurradas nos estados de Alagoas e Pernambuco, despertaram e expuseram a fragilidade e o despreparo da população e da administração pública em lidar com situações extremas e despertaram perguntas da sociedade brasileira: o que está errado? O que pode ser feito? $\mathrm{O}$ que pode ser feito?

Não é intuito deste trabalho ter a pretensão de responder perguntas tão complexas, mesmo que aparentemente diretas e elementares, mas, sim, escrever sobre uma componente significativa do processo relacionado à percepção de riscos dos morados do entorno da Barragem do DNOS, na cidade de Santa Maria - RS.

O objetivo deste trabalho é de diagnosticar, junto aos moradores, aspectos relacionados à percepção de riscos na paisagem do entorno da Barragem do DNOS, localizada na área urbana do município de Santa Maria - RS.

\section{FUNDAMENTAÇÃO TEÓRICA}

\section{I dos conceitos e estado da arte no estudo da percepção em geografia}

Em seus anos iniciais, a Psicologia Ambiental se caracterizou por investigações dispersas sobre as relações do ser humano com o seu ambiente, mediante análise atomista (relacionada à linguagem), segundo a qual a percepção de um objeto era dada pelas partes componentes, organizada posteriormente por associação. Tal ciência, mais precisamente, levantava questões acerca do comportamento do homem em relação aos ambientes construídos - salas, moradias, edifícios, cidades inclusive discutindo mapas psicológicos, condições de estresse e de satisfação residencial e natural. Era uma ciência de controle laboratorial e de caráter psicologista (MARIN, 2008).

$\mathrm{Na}$ ciência geográfica, no contexto da atualidade, os estudos de percepção ambiental, vêm cada vez mais adquirindo importância fundamental, no sentido de possibilitar e melhorar a compreensão das interelações entre o homem e o meio ambiente.

Nessas pesquisas são evidenciados como as características ambientais do espaço geográfico podem influenciar os indivíduos em conjunto com suas emoções e sentidos, fornecendo assim, elementos para mensurar e avaliar situações, e, a partir daí, direcionar suas atividades e seu modo de vida.

Para a Geografia, ao realizar-se qualquer interpretação dentro deste estudo, faz-se necessário o entendimento do conceito "percepção". Para entender a percepção, ressalta-se que as interações do indivíduo com o meio ambiente ocorrem por um processo mental, através de mecanismos perceptivos, os quais são dirigidos por estímulos externos e captados pelos sentidos, ou seja, o Processo de Percepção.

Os mecanismos cognitivos compreendem a contribuição da inteligência, agindo em conjunto com os sentidos e desencadeando os processos mentais de percepção desde a motivação até a decisão de conduta. Incluídos nestes mecanismos se encontram, ainda, os conhecimentos prévios, iniciativas, valores, julgamentos, senso de humor, expectativas e por fim, os níveis de satisfação (GOLD, 1980).

Portanto, como forma de definição, o mesmo autor argumenta:

Cognição é o processo psicológico por meio do qual o ser humano obtém, armazena, usa e opera informações. Incluem sentimento, percepção, memória, julgamento, decisão, ajustamentos e muitos outros processos mentais relativos à experiência e ao comportamento. Percepção, como termo mais específico, é a função psicológica que habilita o indivíduo a transformar o estímulo sensor em experiências coerentes e organizadas. (GOLD, 1980, p. 63).

Estes elementos em conjunto estabelecem a integração do indivíduo com o meio ambiente e também a consciência deste em relação ao espaço, 
sua construção e a sociedade à qual está inserido.

No entanto, algumas correntes da psicologia, que estudam o fenômeno da percepção, afirmam que este processo está ligado ao da significação, sobretudo porque para cada estímulo vindo do meio ambiente, a mente humana vai criando novos significados.

Segundo Piaget (1975), a construção progressiva das relações espaciais se processa em dois planos: no plano perceptivo ou sensório-motor e no plano representativo e intelectual. A mente exerce parte ativa na construção da realidade percebida, e consequentemente na definição de conduta, pois o homem processa mentalmente as informações que o meio ambiente e a herança lhe oferecem, e a conduta que constrói mediante o equilíbrio entre fatores internos e externos.

Para Oliveira (1996, p. 3), "a percepção é um processo mental de interação do indivíduo com o meio ambiente que se dá através de mecanismos perceptivos propriamente ditos e, principalmente cognitivos".

Nesse sentido, as experiências, as vivências, não devem constituir simples momentos na vida de um sujeito: precisa ser por ele apreendidas, adquirir uma significação, ter seu sentido revelado. Tal revelação se alcança pela aplicação do método fenomenológico, que será discutido a seguir.

\section{2 a fenomenologia e os estudos de percepção ambiental}

É provável que o termo fenomenologia tenha sido cunhado pela escola de Christian Wolff, sendo que J. H. Lambert (1728-1777), discípulo de Wolff, utiliza-o, pela primeira vez, como título da quarta parte do seu Novo Organun (1764), referindo-se à fenomenologia como a teoria da ilusão sob suas diferentes formas (DARTIGUES, 1992; ABBAGNANO, 2003).

Em linhas gerais, Husserl (1962) pensava em transformar a Fenomenologia em uma ciência exata, mediante a aplicação rigorosa do método fenomenológico. No entanto, diferentemente das ciências tradicionais cartesianas, tal filósofo argumenta que a realidade não se encontra fora da consciência perceptiva do Homem. A ampliação desse movimento filosófico, a partir de uma perspectiva existencialista, foi oportunizada através de relevantes contribuições, sobretudo as do filósofo francês Maurice Merleau-Ponty (1908-1961).

No campo fenomenológico, o espaço tornou-se objeto muito importante para pesquisa geográfica. Nesse processo, as categorias geográficas são interdependentes e isso resulta num campo fértil para estudo do espaço a partir de sua interação entre o lugar, a paisagem, a região e o território, visando manter as relações entre fenômenos que se manifestam a todo instante no espaço.

Observa-se que o espaço está relacionado com a visão e a percepção do sujeito. Nesta concepção é essencial destacar que a presença do homem enquanto sujeito, que percebe este mundo, como um ser inserido no mundo, implicaria no estar próximo, mantendo relações com os objetos e os outros sujeitos na representação do espaço. De acordo com Merleau-Ponty (1999), o espaço não é um sustentáculo dos objetos ambientais, sejam eles reais ou lógicos. De um lado, torna-se o meio que possibilita a posição destes objetos.

Portanto, para Merleau-Ponty (op. cit.), mundo é aquilo que se percebe e não fruto do significado mundo. Desta forma:

(...) tudo aquilo que sei do mundo, mesmo que por ciência, eu sei a partir de uma visão minha ou de uma experiência do mundo sem a qual os símbolos da ciência não poderiam dizer nada [...] Retornar às coisas mesmas é retornar a este mundo anterior ao conhecimento do qual o conhecimento sempre fala. (MERLEAU-PONTY, 1994, p.3).

Neste sentido, conhecer fenomenologicamente a paisagem implica entende-la não somente como abstrata, objetiva, ou neutra, independente dos elementos que com que ela se relaciona, mas como experiência através dos sentidos: como vivida. É a partir desta perspectiva que será desenvolvido o conceito de paisagem neste capítulo.

\section{3 do estudo da paisagem em geografia}

$O$ estudo da paisagem vem contribuindo para discussões nos campos teórico-metodológico da Geografia, de modo a buscar uma melhor compreensão conceitual, essa que é uma das principais categorias analíticas da ciência geográfica. Nesse sentido, a noção de paisagem está presente na memória do ser humano antes mesmo da elaboração do conceito.

Para Jellycoe; Jellycoe (1995), as expressões desta memória e da observação podem ser encontradas nas artes e nas ciências das diversas culturas, que retratavam inicialmente elementos particulares como animais selvagens, um conjunto de montanhas ou um rio. As pinturas rupestres são uma referência para esta percepção direcionada a alguns componentes do ambiente. Jellycoe; Jelly- 
coe (op. cit.) mencionam as pinturas rupestres da França (Lascaux) e norte da Espanha, como as primeiras concepções conscientes do ser humano a respeito de paisagem. As pinturas datam de período entre 30 mil e 10 mil anos A.C., e são os registros mais antigos que se conhece da observação humana sobre a paisagem.

Em cada época, a compreensão deste tema foi influenciada pela Filosofia, busca da estética, política, religião, ciência, dentre outros aspectos. Além destes, é bem provável que as características naturais, dominantes em cada paisagem, tenham estimulado, ou desencorajado, a relação dos diferentes grupos humanos sobre a face da terra com o seu entorno.

Assim, o conceito de Paisagem é a melhor via de estudo acerca da realidade, pois, uma entidade global possui elementos que a constituem e que participam de uma dinâmica comum (BERTRAND, 2004). Mas, acessar esse conhecimento requer um exercício metodológico que permita observar seus componentes de forma separada e identificar as chaves de seu funcionamento, visto que cada escala possui uma chave distinta.

O processo de percepção ambiental se inicia com a percepção direta, imediata, multissensorial e seletiva do ambiente. O indivíduo seleciona, de acordo com seus valores e suas experiências, as diversas informações existentes no ambiente que o cerca. Só após o recebimento de tais estímulos ambientais, é que o indivíduo parte para o mapeamento mental, chamado de processo cognitivo. Esse mapeamento é resultante das informações recebidas e selecionadas por ele próprio Collot (op. cit.).

Formadas essas imagens, o indivíduo atribui valores, julga e avalia, descrevendo as qualidades do ambiente percebido, definindo preferências que o impulsionam a adotar uma conduta ambiental ou o leva à ação ambiental proveniente de condutas e expectativas próprias.

Ainda para Collot (1990), fenômenos devem ser analisados a partir da intencionalidade, através da consciência de cada indivíduo, portanto, a realidade do espaço geográfico é expressa de maneira única em cada paisagem. Assim sendo, a percepção demonstra aspectos intencionais subjetivos de compreensão da realidade que cerca cada indivíduo.

Desse modo é que a percepção ambiental ganha destaque nos estudos geográficos e, nesse sentido, a seguir é desenvolvida a discussão acerca do conceito de percepção ambiental.

\section{CARACTERIZACC̃̃O GEOGRÁFICA DO MUNICÍPIO DE SANTA MARIA E DA ÁREA DE ESTUDO}

Este estudo tem como indicador espacial, o entorno da Barragem do Departamento Nacional de Obras e Saneamento (DNOS), cuja localização pode ser visualizada na Figura 01.

\section{I características físicas da área de estudo}

Constituindo a porção norte do município ocorrem os derrames de lava da Formação Serra Geral. A Formação Serra Geral é constituída por duas sequências vulcânicas: uma básica e outra ácida (Maciel Filho, 1990).

Nesse contexto, Sartori (op. cit.) destaca a formação Serra Geral da seguinte maneira:

Após um longo período de erosão continental, durante o Jurássico, o ambiente desértico estabelecido e iniciado com a sedimentação de arenitos eólicos foi seguido, no início do Cretáceo, por extensa atividade vulcânica relacionada à abertura do Atlântico Sul, o que recobriu parcialmente essa sequência sedimentar de forma transgressiva - inicialmente com derrames de lavas básicas, por fusões parciais advindas do Manto Superior com assimilação crustal e, posteriormente, com a ascensão dos derrames de lavas ácidas provenientes de fusões parciais na base da Crosta Continental. (SARTORI, 2009, p.19).

Dessa forma, o Planalto da Bacia do Paraná, resultante da superposição dos sucessivos derrames de lavas do vulcanismo Mesozóico que ocorreu na bacia sedimentar, apresenta desnível da ordem de $370 \mathrm{~m}$, entre seu topo e as terras baixas da Depressão, já que as altitudes maiores situamse em torno dos 500 metros (SARTORI, 2000).

A configuração do relevo evoluiu, a partir do Terciário, por processos erosivos associados aos climas úmidos, alternados com climas áridos e semiáridos, processos que comandaram a esculturação da paisagem atual (SARTORI, 2009).

Por isso o relevo atual do município de Santa Maria caracteriza-se pela presença do topo e rebordo do Planalto da Bacia do Paraná, com a morfologia de vales e morros, e da Depressão Periférica Sul-rio-grandense, com modelado de colinas (coxilhas) e planícies aluviais (SARTORI, 2009).

Nesse sentido, a Barragem do DNOS, objeto desse estudo, situa-se no Rebordo do Planalto da Bacia do Paraná, em uma área de transição entre 


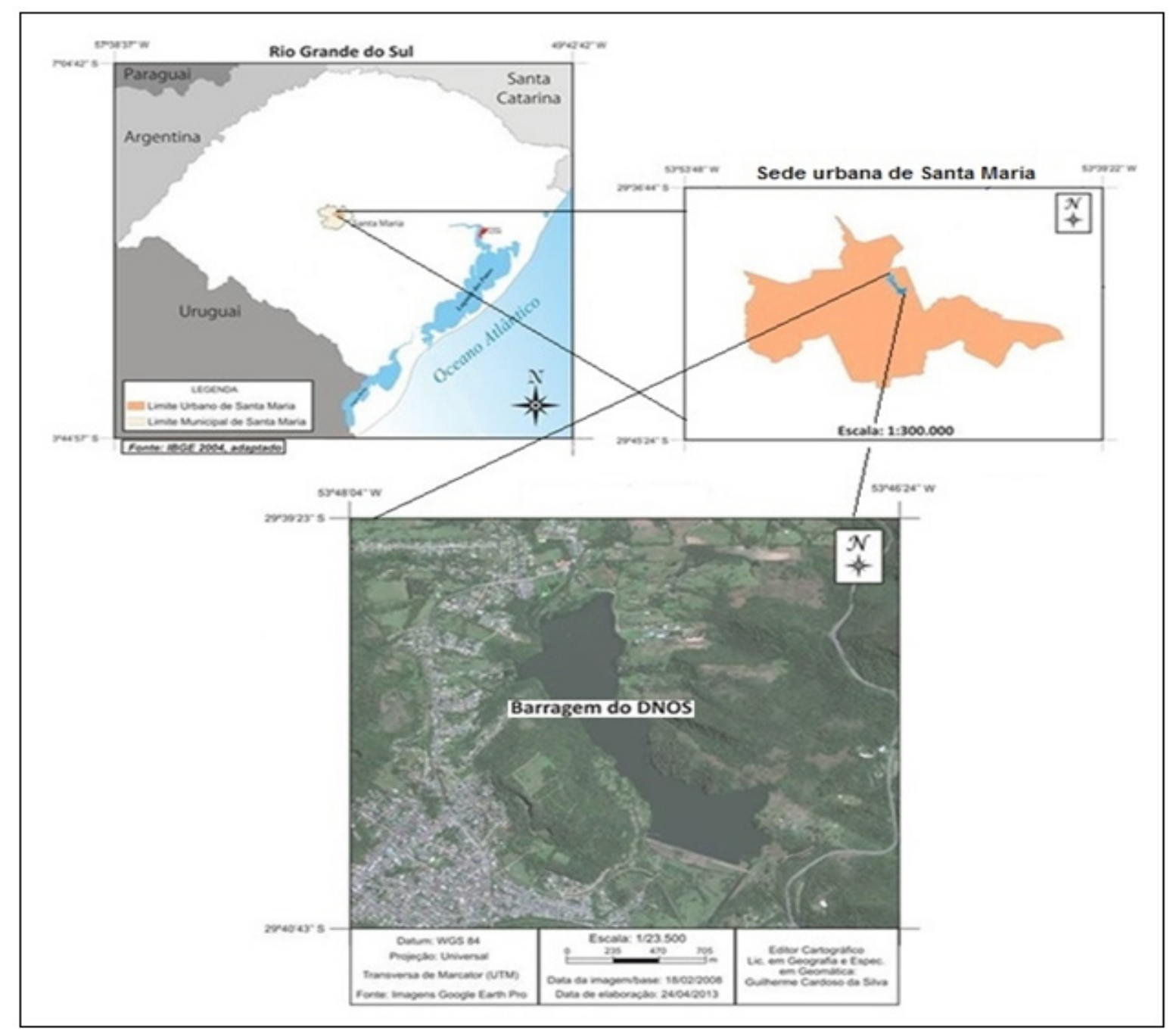

Figura 01: Mapa de localização da Barragem do DNOS - Santa Maria - RS.

Org.: Os autores (2013).

a Depressão Periférica Sul-rio-grandense, com presença de vales e montanhas.

Condicionantes geoecológicos do sítio urbano de Santa Maria, como a proximidade do Rebordo do Planalto e sua vegetação possivelmente exercem influência sobre o campo térmico das áreas próximas a este compartimento geomorfológico. Do ponto de vista climático, o município de Santa Maria de acordo com Sartori (2000), apresenta temperaturas médias do mês mais frio (julho) entre $13^{\circ} \mathrm{C}$ e $15^{\circ} \mathrm{C}$ e a média das mínimas entre $7^{\circ} \mathrm{C}$ e $10^{\circ} \mathrm{C}$, provocadas pelas invasões periódicas do Anticiclone Polar Atlântico, que traz a Massa Polar Atlântica.

Nos verões, a temperatura média do mês mais quente (janeiro) é superior a $24^{\circ} \mathrm{C}$ e a média das máximas varia entre $27^{\circ} \mathrm{C}$ no topo do Planalto (mais ou menos $500 \mathrm{~m}$ ), e $32^{\circ} \mathrm{C}$ na Depressão (40 a $130 \mathrm{~m}$ ), provocadas por superaquecimento continental de massas polares e, embora de menor frequência de massas tropicais (Massa Tropical Atlântica ou Massa Tropical Continental). (SARTORI, 2003).

As temperaturas médias anuais variam entre $23^{\circ}, 8^{\circ} \mathrm{C}$ e $25^{\circ}, 5^{\circ} \mathrm{C}$, enquanto as médias das mínimas do ano situam-se entre $12^{\circ} \mathrm{C}$ e $14^{\circ} \mathrm{C}$, no Planalto e Depressão, respectivamente.

A vegetação original do Rebordo do Planalto caracteriza-se pela sazonalidade do clima na região, que de acordo com Pereira, Garcia, Netto, Borin, Sartori (et. al, 1989) é a Floresta Subcaducifolia Subtropical que aparece onde existem condições favoráveis ao seu desenvolvimento, como: maior umidade do ar, chuvas abundantes e nevoeiro frequente, como existem na área de estudo, além disso, os vales também facilitam o desenvolvimento florestal porque protegem contra as rápidas variações de temperatura no inverno e funcionam como estufa no verão. $\mathrm{Na}$ área de estudo a floresta já se apresenta bastante modificada pela 
ação antrópica passada e atual, com invasão de moradias em locais de riscos ambientais.

\section{2 características sócioeconômicas}

Com uma população de 261.027 habitantes em 2010 (IBGE), Santa Maria constitui-se numa cidade de médio porte, caracterizada pela prestação de serviços educacionais, de saúde, comercial e militar, mas também em importante centro político-econômico regional e grande pólo de atração populacional. Sua crescente projeção como centro educacional a torna, conforme observa Sartori (2000), no mais importante centro urbano do interior do Rio Grande do Sul neste setor, com ampla área de atuação, onde milhares de jovens de outras localidades (mesmo fora do Estado) se estabelecem à procura das escolas de Ensino Médio e dos cursos de graduação e pós-graduação oferecidos pela Universidade Federal de Santa Maria e outras particulares.

No que diz respeito à ação antrópica, marcada pelas ocupações irregulares, como em parte do entorno da barragem do DNOS, chama a atenção as habitações na encosta do Morro Cechella (Cerro Santa Maria), e a segregação social e espacial, considerando o alto risco de deslizamentos que a encosta do morro pode causar, especialmente, em épocas de chuvas acentuadas ou duradouras na região de Santa Maria, que podem acontecer em qualquer estação do ano.
Nesse contexto, observam-se características da expansão e do crescimento urbano de boa parte da cidade de Santa Maria, na qual ocorre, segundo BOLFE (2003), a problemática que envolve a questão da moradia e da regularização fundiária, fato antigo em Santa Maria, chamada "Cidade das Invasões", devido às várias ocupações que se estendem desde a década de 60 e 70 na cidade.

Entretanto, o eixo de maior expansão urbana se deu na direção leste-oeste, em decorrência dos entraves físicos do rebordo do Planalto (Serra Geral) ao norte e os morros testemunhos a sudeste, que impediram e impedem a ocupação humana.

\section{METODOLOGIA DE PESQUISA}

Esta pesquisa tem uma abordagem qualitativa, visto que queremos saber a percepção de risco dos moradores do entorno da Barragem do Departamento Nacional de Obras e Saneamento (DNOS), sujeitos da investigação. Uma pesquisa qualitativa, ao valorizar os aspectos descritivos e as percepções pessoais, procura compreender os sujeitos envolvidos e, por seu intermédio, avaliar também o contexto em que vivem (BOGDAN; BIKLEN, 1994), através de valores, crenças, atitudes, representações, significados, opiniões e visões de mundo expressos na linguagem comum e na vida

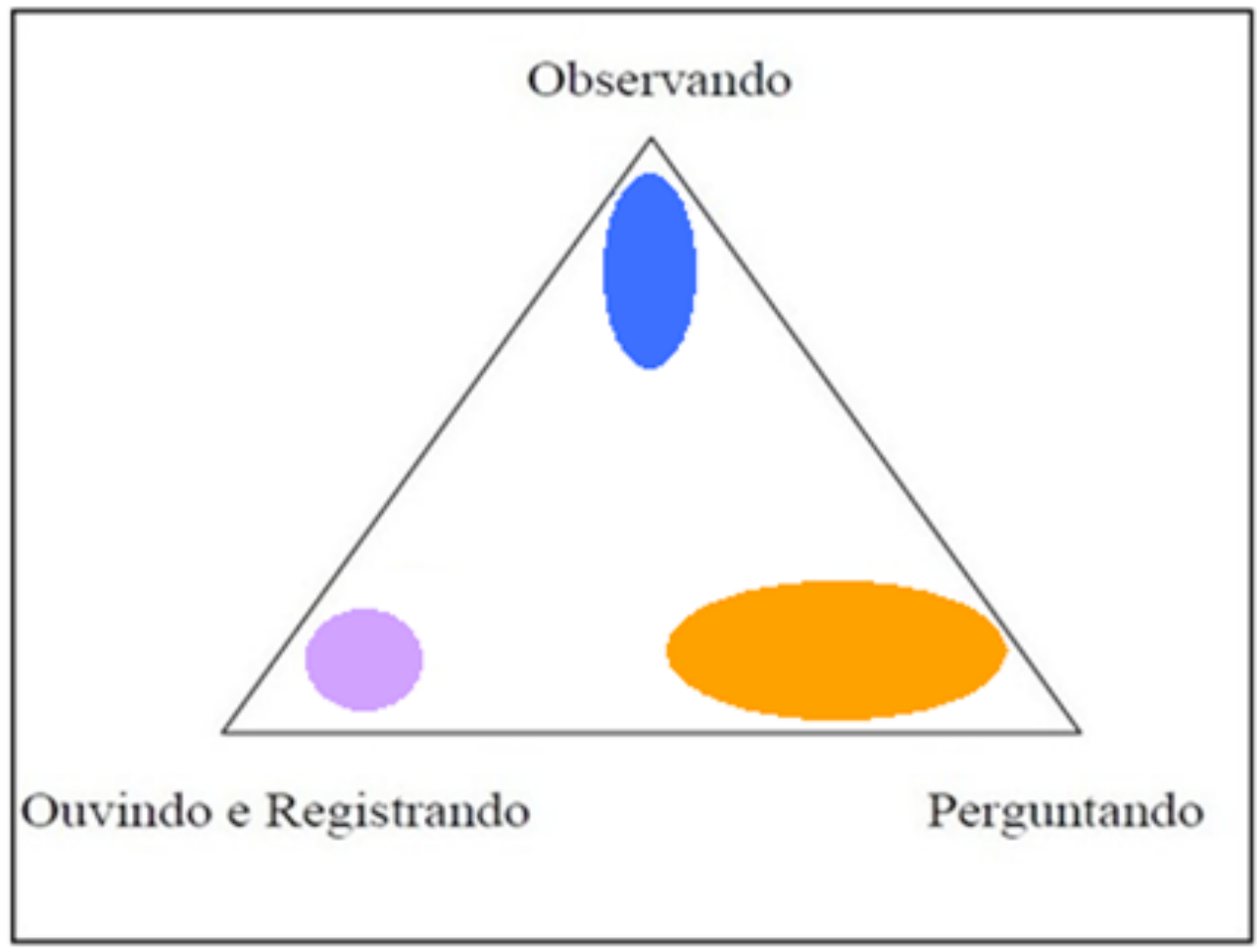

Figura 2: Triângulo Metodológico da Pesquisa.

Fonte: Adaptado de Whyte (1977). 
cotidiana dessas pessoas. Uma pesquisa qualitativa "trabalha" com informações subjetivas de locais e de fatos, fornecidas pelos sujeitos envolvidos.

Inicialmente partiu-se de uma revisão da literatura para compor a fundamentação teóricometodológica que servisse de base para o desenvolvimento da proposta deste trabalho, que visou analisar se os moradores do entorno da Barragem do Departamento de Obras e Saneamento (DNOS) desenvolveram percepção de risco em relação à paisagem que constitui o seu lugar de vivência diária, bem como as atitudes e valores que envolvem essa paisagem do entorno da represa. Assim, num primeiro momento foi feita a definição da área para estudo de percepção da população, tendo-se então, como recorte espacial, o entorno da Barragem do DNOS, a nordeste do perímetro urbano de Santa Maria.

Dessa forma, partiu-se para bibliografias que abordassem temas semelhantes para desenvolver a pesquisa, bem como para as que abordassem temas de cunho metodológico.

Para a realização da pesquisa os instrumentos utilizados foram o levantamento do material bibliográfico essencial para o embasamento teórico e material cartográfico (imagem de satélite, cartas topográficas e mapas), correspondente à área de estudo.

Neste trabalho, a metodologia adotada foi a proposta por Whyte (1977), igualmente utilizada por Sartori (2000), que sugeriu que os estudos de percepção ambiental podem ser conduzidos mediante abordagens que compõem o "triângulo metodológico" de pesquisa, sendo, dos 4 métodos de análise, foram selecionados três: "Observando, Perguntando e Ouvindo e Registrando" (Figura 2), Sartori (2000) explica, didaticamente, o que significa cada uma destas estratégias metodológicas.

O "Observando" representa a atenção e a preocupação com as técnicas aplicadas durante os trabalhos de campo realizados no decorrer da pesquisa, assim com o reconhecimento e delimitação de área em estudo, já explicado anteriormente, podendo ser definida como de Observação direta e de Observação Participante; no último caso quando se utiliza "informantes".

No "Perguntando" enquadram-se as Entrevistas com questões abertas, fechadas ou questões mistas, que podem ser classificadas como Padronizadas e Não Padronizadas. Neste sentido, Marconi; Lakatos (1982) colocam que "a entrevista padronizada possui um roteiro previamente estabelecido com perguntas pré-determinadas, podendo ser na forma de questionários e de formulários", principal abordagem utilizada neste trabalho.

O "Ouvindo e Registrando" é uma abordagem do "tipo história oral", na qual as percepções são definidas em conversa com as pessoas que tenham vivenciado diretamente os eventos ambientais ou que falam sobre alguns fatos que elas foram transmitidas.

Nesse sentido, foram aplicadas sete (07) perguntas à população residente no entorno da barragem do DNOS, sendo três (03) desencadeadoras, e as outras quatro (04) sobre a percepção dos riscos, conforme objetivo da pesquisa. As questões serão citadas e melhores explicadas à luz do conhecimento fenomenológico no item 5 desta pesquisa.

\section{DOS RESULTADOS DA PESQUISA: A PERCEPÇÃO DOS MORADORES EM RELAÇÃO AO RISCO AMBIENTAL NO ENTORNO DA BARRAGEM DO DNOS}

Como já foi dito anteriormente, a pesquisa qualitativa, pelo tipo de técnicas que emprega não

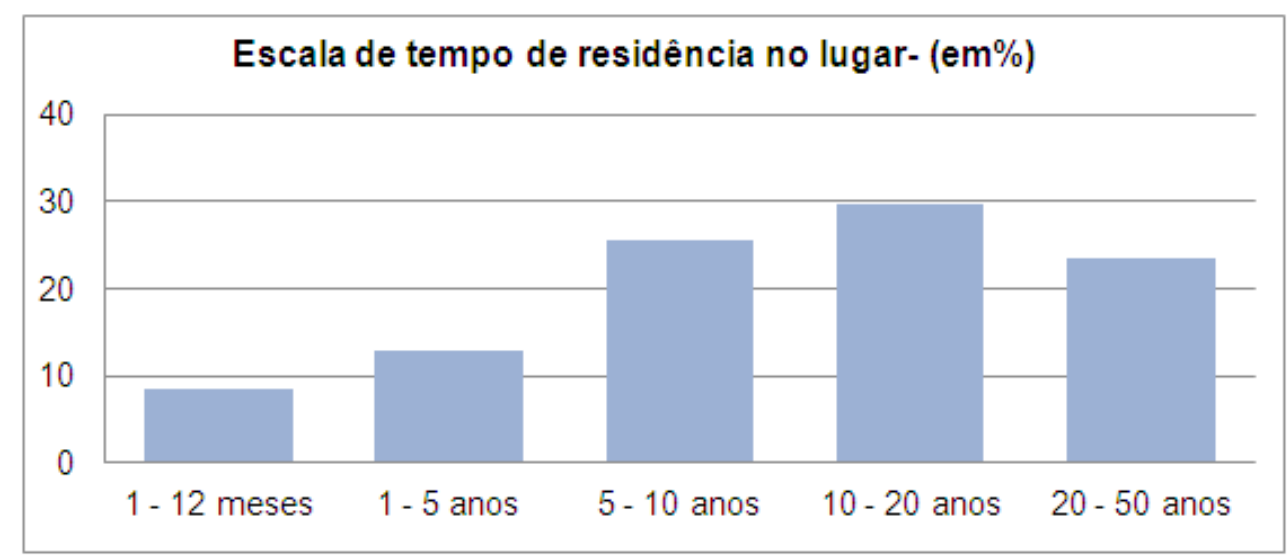

Figura 3 - Gráfico sobre o tempo de residência no lugar.

Org.: Os autores (2013) 


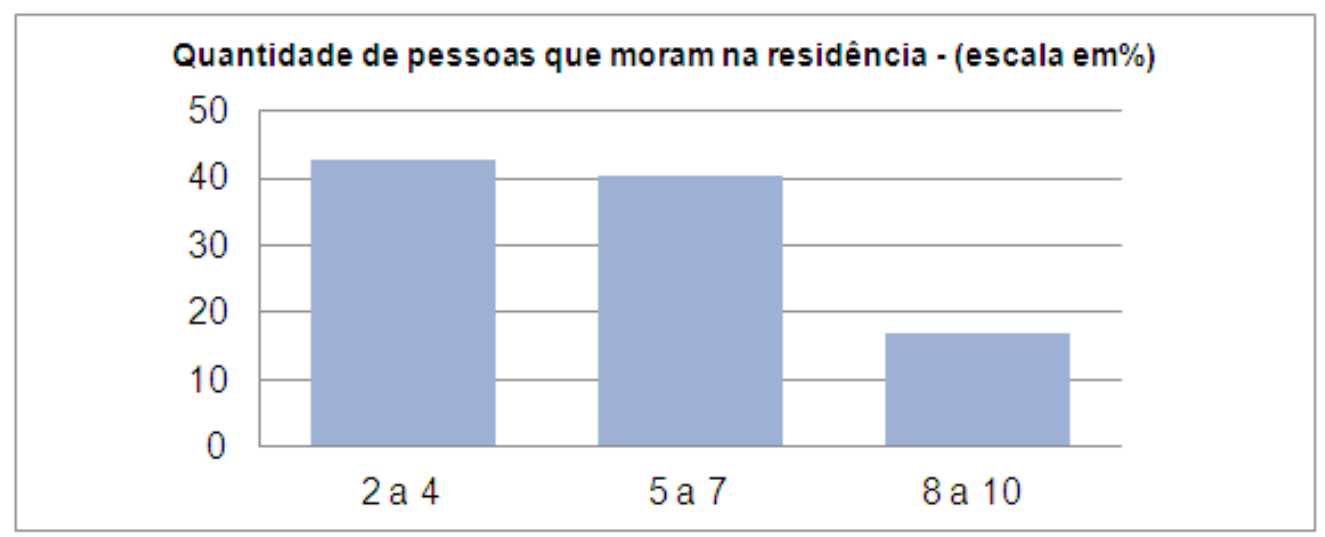

Figura 4 - Gráfico da quantidade de pessoas que moram na residência.

Org.: Os autores (2013).

estabelece separações estanques entre a coleta e a interpretação das informações. Existe um fluxo constante de informações que são levantadas, logo após são interpretadas, podendo surgir novas questões. (Triviños, 1992).

A primeira questão fechada, referente ao tempo de residência no local (Figura 3), foi classificada de acordo com o período que cada entrevistado possui de vivência no lugar onde foi realizada a pesquisa. Desta forma, 30\% dos entrevistados declararam morar no lugar entre 10 a 20 anos, $25 \%$, de 5 a 10 anos, $24 \%$ de 20 a 50 anos, $13 \%$ de 1 a 5 anos e, $8 \%$ de 1 a 12 meses.

Com relação a essas questões, a experiência dos sujeitos no local de moradia é fator preponderante, já que amplia as possibilidades de convivência com as situações de risco, produzindo consequências sobre a percepção. Em se tratando do tempo de moradia no bairro, é possível afirmar que os sujeitos da pesquisa têm experiência mais que suficiente no local, principalmente se for considerado o número de escorregamentos ocorridos ao longo desse período, ou até os mais antigos - como o grande escorregamento que houve na década de 1960, relatado por um morador de 73 anos.

Como muitos moradores estão instalados na vertente leste do Morro Cechella desde o início de sua ocupação, tiveram oportunidade de acompanhar todo o processo de crescimento do bairro, suas implicações na ocorrência de escorregamentos e as relações estabelecidas entre a comunidade local e o poder público, seja por meio da Prefeitura Municipal, Defesa Civil, bem como através dos Bombeiros.

A respeito da segunda questão a qual se refere ao sexo dos entrevistados, $74 \%$ dos entrevistados são do sexo feminino e $26 \%$ do sexo masculino. Desta forma, de acordo com Tuan (1980), pode haver diferenciações na percepção ambiental entre os sexos, tendo o sexo feminino, uma percepção mais apurada do que o sexo masculino.

Com relação à terceira questão, que aborda sobre a escolaridade dos entrevistados (Figura 18), $53 \%$ declararam possuir apenas as Séries Iniciais do Ensino Fundamental $\left(1^{\mathrm{a}}\right.$ a $4^{\mathrm{a}}$ series); $41 \%$ possuem entre $5^{\mathrm{a}}$ e $8^{\mathrm{a}}$ série; os $6 \%$ restantes possuem o Ensino Médio incompleto e, nenhum entrevistado possui o Ensino Médio concluído.

Esse fato se traduz em graves implicações quanto à vulnerabilidade desses moradores, já que a baixa escolaridade os exclui na disputa do mercado de trabalho, impondo-os ao desemprego e ao mercado informal, o que repercute em baixa renda, em habitações precárias e baixa qualidade de vida. Assim, essa população é menos propensa a uma resposta positiva quando da ocorrência de algum evento adverso. Em todas as faixas etárias foram constatadas baixa escolaridade.

A quarta questão (Figura 4), aborda a quantidade de pessoas que moram na residência. $43 \%$ dos entrevistados relataram conviver com 2 a 4 pessoas em sua residência, $40 \%$ de 5 a 7 pessoas, e, $17 \%$ de 8 a 10 pessoas por domicilio.

Dessa forma, Carneiro e Veiga (2004) concluem que vulnerabilidades e riscos remetem às noções de carências e de exclusão. Pessoas, famílias e comunidades são vulneráveis quando não dispõem de recursos materiais e imateriais para enfrentar com sucesso os riscos a que são ou estão submetidas, nem de capacidades para adotar cursos de ações/estratégias que lhes possibilitem alcançar patamares razoáveis de segurança pessoal/ coletiva. Nesse sentido, um destes patamares pode ser o aspecto do planejamento familiar.

Na percepção ambiental, há outros fatores que podem influenciar a forma como o ser 


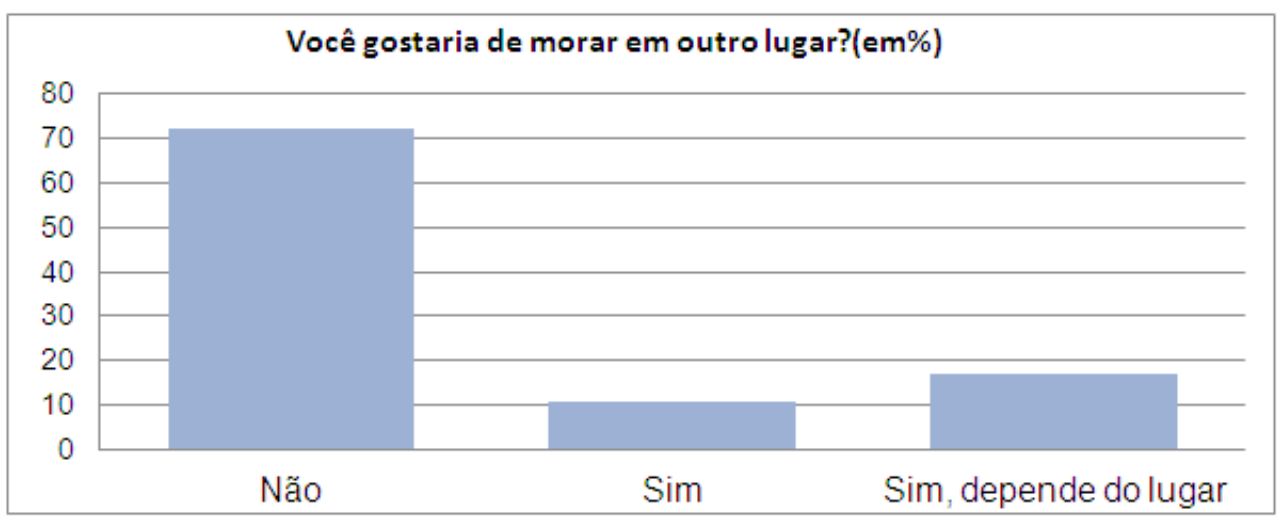

Figura 5- Gráfico que demonstra se o entrevistado gostaria de morar em outro lugar.

Org.: Os autores (2013).

humano interage com o mundo, por exemplo, a idade. Assim, este componente é uma variável significativa no processo da percepção ambiental e na forma de o homem apreender a paisagem experenciada, pois cada um possui os elementos para perceber o mundo de acordo com sua experiência e seu olhar geográfico.

Com relação à quinta questão (Figura 5), questiona se o entrevistado gostaria de morar em outro lugar. $72 \%$ dos entrevistados responderam que não gostariam de morar em outro lugar; $10 \%$ disseram que sim, gostariam; e, 18\% disseram que sim, porem, depende do lugar.

Por meio destes dados observa-se que o lugar onde os entrevistados residem é percebido como uma paisagem topofílica, que além de reforçar a resposta acima, retrata a topofilia expressa por Tuan (1980), ao defini-la como o elo afetivo que a pessoa ou um determinado grupo de pessoas tem em relação ao lugar ou ambiente físico.

Desta forma, um entrevistado de 52 anos relata que: "o lugar onde nós moramos é muito bonito, tem uma paisagem que nenhum outro lugar que se possa morar tem uma beleza como esta". Possivelmente o entrevistado quis se referir à interação da vegetação que ainda esta preservada na encosta leste do Morro Cechella, conjugando uma paisagem única de vale e morros que compõe o entorno da Barragem do DNOS.

Ou ainda, segundo Moreira (2005), o programa MBA/UNESCO compreende a percepção do meio ambiente nos estudos das interações o ser humano e a natureza, que além de perceber sensorialmente o ambiente, permite auxiliar nas decisões e nas ações antrópicas.

Então, algumas pessoas perceberam que o entorno da Barragem do DNOS é um ambiente favorável para que haja a interação entre homemnatureza. Desta forma, para alguns moradores, apesar dos riscos, o lugar é perfeitamente habitável.

Com relação à questão seis, que pergunta se o entrevistado tem vontade de sair do atual lugar

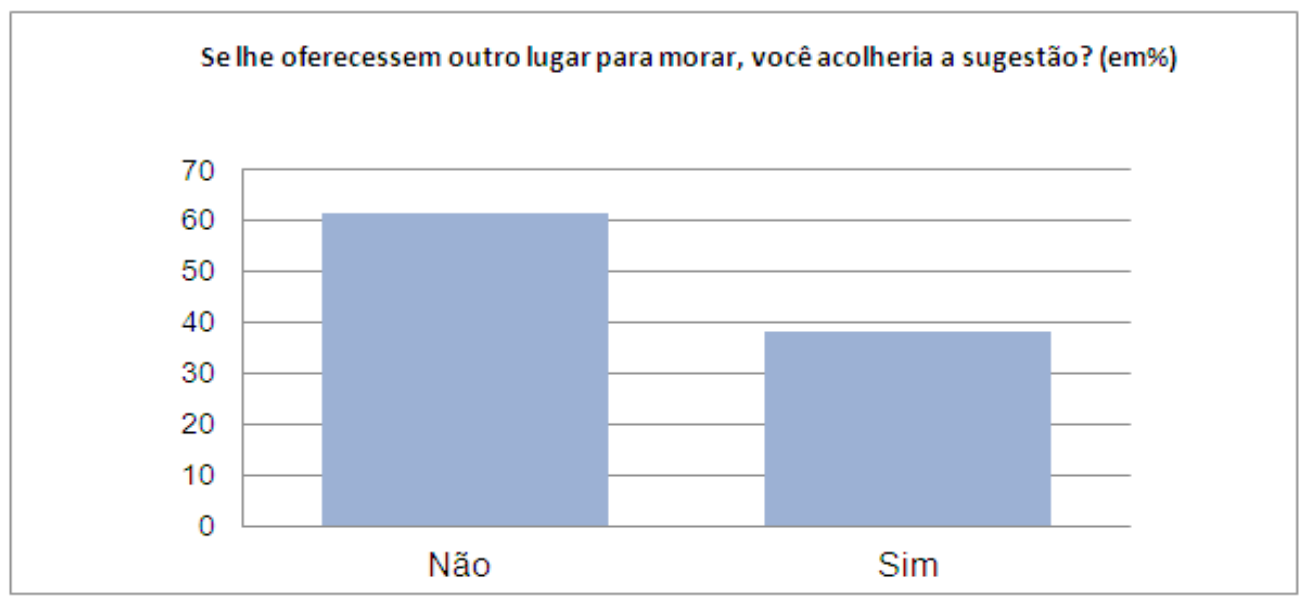

Figura 6 - Gráfico que afere se o entrevistado acolheria a sugestão de morar em outro lugar se fosse lhe oferecido. Org.: Os autores (2013). 
onde ele reside. $75 \%$ dos entrevistados disseram que não tem vontade de sair do lugar onde eles moram; contudo, $25 \%$ responderam que sim, tem vontade de sair do atual lugar ao qual residem.

Estes resultados contribuem para ratificar a analise da questão 5, a qual expressa o sentimento de topofilia que os moradores representam ter do lugar onde vivem atualmente. Observase isso pelo fato dos laços afetivo entre parentes e amigos já estarem estabelecidos na comunidade, bem como a própria paisagem que os moradores destacaram como um fator preponderante para eles quererem permanecer neste lugar para viverem.

A respeito da questão sete (Figura 6), que afere se o entrevistado acolheria a sugestão de morar em outro lugar se fosse lhe oferecido. $62 \%$ dos entrevistados responderam que não acolheriam a sugestão de morar em outro lugar; e, apenas 38\% aceitariam a sugestão.

Os resultados desta questão corroboram, mais uma vez, aos dados das questões 5 e 6 , as quais diagnosticaram o sentimento de topofilia dos entrevistados com o lugar a onde estão estabelecidos.

Apesar de 38\% dos entrevistados responderem que acolheriam a sugestão de morar em outro lugar, vale salientar que praticamente todos ressaltaram que apenas aceitariam se este lugar fosse consideravelmente melhor do que o lugar que eles vivem atualmente.

\section{CONSIDERAÇÕES FINAIS}

A intenção de realizar uma pesquisa estudando a percepção das pessoas sobre o risco ambiental, certamente foi o maior e o mais geral dos desafios deste trabalho. Porém, vários outros, de significativa dificuldade, também estiveram presentes nessa pesquisa. Essas outras dificuldades destacam-se a escolha do caminho teórico-metodológico, a seleção da escala espacial de análise, as análises das entrevistas, e abordagem geográfica que levava em consideração aspectos da relação do homem com seu ambiente.

A partir desse plano de fundo definiu-se o principal objetivo, que foi compreender a interação entre as populações e os fenômenos ambientais, sociais e políticos que os tornavam vulneráveis a riscos, além de sistematizar discussões acerca da proposta de melhoria que abarcassem as experiências dos moradores de áreas de risco.

A hipótese inicial foi formulada na constatação de que essa interação ocorre espacialmente, e é intermediada pela existência de riscos ambientais e que as pessoas vulneráveis não possuíam entendimento adequado da gravidade dos problemas com os quais elas convivem. Embora pudesse parecer que a hipótese fosse um tanto evidente para o meio cientifico, pode-se considerá-la fundamental no atual contexto, no qual as políticas técnicas e públicas não vêm conseguindo sanar ou prevenir as perdas da população.

Os estudos futuros nessa área devem considerar populações mais amplas, de vários níveis socioeconômicos e educacionais. Com esses dados, será possível relacionar características sócio-demográficas com os níveis de percepção e cognição da percepção da paisagem pelos moradores. Os estudos devem incluir perguntas sobre o que foi feito realmente quando o evento aconteceu em termos das ações realizadas pelas pessoas. Não se pode esquecer de que algumas áreas do entorno da Barragem do DNOS aconteceram, historicamente, desastres naturais, pois estes não ocorrem em um vácuo e, que as ações que são realizadas pelas pessoas são elementos de um sistema cultural, social, político e econômico complexo.

Existe necessidade de pesquisas sobre percepção na paisagem. Tal necessidade se encontra atrelada ao aumento demográfico, assim como o aumento da população urbana no mundo. O desenvolvimento de estratégias eficazes da administração de risco requer tanto o conhecimento do ambiente físico como dos processos sociais, psicológicos e econômicos que podem afetar as respostas das pessoas às condições ambientais de perigo.

\section{REFERÊNCIAS}

ABBAGNANO, Nicola. Dicionário de filosofia. São Paulo: Martins Fontes, 2003.

BERTRAND, G. Paisagem e geografia física global. Esboço metodológico. Revista RA'E GA, Curitiba, n. 8, p. 141-152. 2004.

BOGDAN, R.; BIKLEN, S. Investigação qualitativa em educação: uma introdução à teoria e aos métodos. Porto, Portugal: Porto Editora, 1994.

BOLFE, Sandra Ana. Transformações do Espaço Urbano de Santa Maria RS e sua região: tendências e Condicionantes. Universidade de São Paulo: USP. 2003. 
CARNEIRO, C. B. L.; VEIGA, L. O conceito de inclusão, dimensões e indicadores. Belo Horizonte: Secretaria Municipal de Coordenação da Política Social, jun. 2004. (Pensar BH - Política Social, 2.)

COLLOT, Michel. Pontos de vista dobre a percepção das paisagens. Boletim de Geografia Teorética, 20(39):21-32,1990.

DARTIGUES, André. O que é fenomenologia? 2.ed. Rio de Janeiro: Eldorado, 1992. 163p.

GOLD, J. R. An introduction to behavioral geography. New York: Oxford University, 1980.

HUSSERL, Edmund. Ideas. Nova York: Macmillan, 1962.

JELLYCOE, G.; JELLYCOE, S. El paisaje del hombre: la conformación del entorno desde la prehistoria hasta nuestros días. Barcelona: Editorial Gustavo Gili, 1995.

MACIEL FILHO, C.L. Carta Geotécnica de Santa Maria (1:25.000). Santa Maria: UFSM, 1990.

MARIN, Andréia Aparecida. Pesquisa em educação ambiental e percepção ambiental. Pesquisa em Educação Ambiental, São Carlos; Sorocaba-SP: UFSCar; Rio Claro-SP: UNESP/IBRC; Ribeirão Preto-SP: USP/FFCLRP, v.3, n.1, p.203-222, jan/ jun. 2008.

MARCONI, M. A.; LAKATOS, E. M. Técnicas de Pesquisa: Planejamento e execução de pesquisas, amostragens e técnicas de pesquisa, elaboração, análise e interpretação de dados. São Paulo: Atlas, 2006.

MERLEAU-PONTY, Maurice. Fenomenologia da percepção. Tradução de: Carlos Alberto Ribeiro de Moura. $2^{\mathrm{a}}$. ed. São Paulo: Martins Fontes, 1999.

. Maurice. Fenomenologia da per-

cepção. Tradução Carlos Roberto Ribeiro Moura. São Paulo: Martins Fontes, 1994. 662p.

MOREIRA, Ana Lucia O. A Floresta: um referencial para a percepção e educação ambiental. 2005. 218 f. Tese (Doutorado)- Centro de Ciências Biológicas, Universidade Federal de São Carlos, São Carlos, 2005.

OLIVEIRA, F. A questão do Estado: vulnerabilidade social e carência de direitos. In: Subsídios à Confe- rência Nacional de Assistência Social, 1. Brasília: CNAS, out. 1996. (Cadernos ABONG).

PIAGET, Jean. O nascimento da inteligência na criança. 2. ed. Rio de Janeiro: Zahar Editores, 1975.

SARTORI. P.L. REVISTA CIÊNCIA \& AMBIENTE. História Natural de Santa Maria. Santa Maria: Universidade Federal de Santa Maria, v. 1, n. 38, jan./jun. 2009.

SARTORI, M.G.B. Clima e Percepção Vol.2. 2000. Tese (Doutorado em Geografia) - Departamento de Geografia/FFLCH/USP, São Paulo, 2000.

TRIVIÑOS, Augusto Nibaldo Silva. Introdução à Pesquisa em Ciências Sociais: a pesquisa qualitativa em educação. São Paulo: Atlas, 1992.

TUAN, Yi-Fu. Topofilia.Um estudo da percepção, atitudes e valores do meio ambiente. São Paulo: Difel, 1980.

WHYTE, A. V. Guidelines for Fields Studies in Environmental Perception: Technical Notes 5. França: UNESCO, 1977. 